\title{
DANÇAR PARA APRENDER
}

Gláucia Bispo ${ }^{\mathrm{i}}$

\begin{abstract}
Resumo: Este relato de experiências é fruto de um desejo antigo. É uma partilha de vivências a respeito de corpos moventes e dançantes no período da Alfabetização. O presente texto apresenta o caminho percorrido por crianças e professora, do $2^{\circ}$ ano do Ensino Fundamental I, que reconheceram a necessidade e o interesse pelo movimento dançante para aprender a aprender, e aprender a ensinar. Dançar foi preciso para que as crianças aprendessem a ler, escrever e contar, assim como foi preciso para que a professora aprendesse a ensinar com uma das potências fundamentais da existência humana: o corpo (em movimento).
\end{abstract}

Palavras-chave: Corpo; Alfabetização; Dança.

\section{DANCE TO LEARN}

\begin{abstract}
This account of experiences is the result of an old desire. It is a sharing of experiences regarding moving and dancing bodies during the Literacy period. This text presents the path taken by children and teacher, from the 2nd year of Elementary School I, who recognized the need and interest in the dance movement to learn to learn and learn to teach. Dancing was necessary for children to learn to read, write and count, just as it was necessary for the teacher to learn to teach with one of the fundamental powers of human existence: the body (in motion).
\end{abstract}

Keyword: Body; Literacy; Dance.

Este relato é fruto de um desejo antigo de compartilhar as experiências que transformaram a minha concepção de escola e modos de ensinagem e aprendizagem. Dançar foi preciso para aprender a aprender, e para aprender a ensinar. Descobri que os corpos em movimento presentes na escola são potências para interações afetivas, significativas, criativas e democráticas. Dançar foi preciso para (re)existir dentro do espaço, por vezes caótico, da escola. Dançamos e aprendemos. Dançamos e ensinamos. Dançamos e (nos) reinventamos.

O ingresso no quadro docente da Secretaria Municipal do Rio de Janeiro (SME/RJ) foi um divisor de águas na minha trajetória profissional. Recém-formada - Pedagogia (UFF, 2012), assumi uma turma de $5^{\circ}$ ano em meados de setembro de 2012. O grupo me recebeu de maneira agressiva e com resistência às atividades escolares que eu propunha. Quase sucumbindo às novidades e não sabendo lidar com as mesmas, pensei em uma possibilidade: "vou fazer o que sei": dancei Frevoii com as crianças. Surpreendentemente o fazer Frevo foi o 
que me fez perseverar naquele contexto e ter o mínimo de esperança em vencer os obstáculos da inexperiência.

O trabalho realizado com esse grupo de crianças foi fundamental para sobreviver na sala de aula e realizar um trabalho pedagógico com a turma. Porém, eu percebia que havia um processo e um resultado satisfatório no fazer artístico, mas não nas atividades escolares (ler, escrever e contar). Afinal, é para isso que eu estava ali. Era essa concepção que tinha de escola.

Nos anos subsequentes insisti na dança - não somente no Frevo, mas também outras modalidades - funk, MPB -, como possibilidade de envolvimento, engajamento e de um fazer artístico. Eu notava que esse fazer era prazeroso e frutífero, mas continuava com o mesmo impasse em relação às atividades escolares. Era bom dançar, mas resistiam em estudar. Demorou para eu perceber que ao dançar, estudávamos, de modo não convencional, mas estudávamos.

Em 2016, com um pouco mais de experiência como regente de turma, assumi um grupo de alfabetização, $1^{\circ}$ ano. Uma grande responsabilidade para quem ainda não havia alfabetizado recém-ingressantes no Ensino Fundamental I. Diante da nova inexperiência, fiz o mesmo: dancei. Entretanto, foi no ano seguinte ( $2^{\circ}$ ano), com o mesmo grupo, que o trabalho tomou forma. Dançamos um pot-pourri de música da cantora Carmem Miranda. As crianças foram alfabetizadas e estrelaram em um Musical, que rendeu ao grupo uma apresentação na XXXV Mostra Municipal de Dança. Essa foi a experiência que modificou minha concepção de escola. Dançar para aprender foi e ainda continua sendo preciso à minha (re)existência na escola.

Em 2017, o Projeto Político Pedagógico da unidade tinha como tema gerador, Músicas Populares Brasileiras (MPB). Na ocasião, foi proposto trabalharmos músicas da década de 1920/1930/1940. Apresentei a cantora Carmem Miranda (1909-1930) às crianças. Não só suas (letras de) músicas, bem como a personagem criada por ela. Montamos um musical com as canções mais famosas da Pequena Notável. Cantamos, dançamos e produzimos os figurinos estilizados que remetiam à cantora. Nos apresentamos à unidade escolar e participamos de projetos de extensividade da Rede, como a Mostra de Dança Regional, chegando a participar da Municipal.

As atividades realizadas em sala de aula nos conduziram à dança como uma consequência inevitável. A sequência didática proporcionava um fazer corporal das crianças e da professora que não gerava indisciplina, gerava movimento. 
Iniciamos sentados, cada criança com a letra da música xerocada em mãos. A curiosidade pelas letras e pela possibilidade de ler um texto maior que o de costume, fez as crianças olharem o papel que recebiam. Em seguida, coloquei para tocar a música $O$ que é que a baiana tem?, de Dorival Sen Caymmi, interpretada por Carmem Miranda. Algumas crianças tentaram acompanhar a letra com o texto em mãos e chacoalhando o corpo no ritmo da música. Outras largaram o papel e dançavam ao seu modo. Um grupo de meninas tremeu os ombros, enquanto riam umas para as outras. Ao final, pediram para repetir a música. E assim foi feito várias vezes.

Na quarta repetição da canção, intervi e solicitei que todos tentassem acompanhar o texto, cantando junto com a intérprete. Muitos gaguejaram, mas tentaram (ação fundamental aos que estão em processo de aquisição da leitura). Um grupo conseguiu identificar várias palavras e um grupo menor conseguiu ler e acompanhar com certa fluência. O que havia de comum em todos eles? Todos realizaram a atividade dançando, fosse em pé, sentado ou no meio da sala segurando o papel (a configuração das carteiras na sala de aula era em "U". Havia, portanto, espaço para o movimento).

Nesse momento não houve mais dúvida: a valorização do corpo das crianças e da professora é essencial para aprender. Dancei junto com a turma e aprendi, dançando, que a turma avançaria, em seu processo de escolarização, com o corpo em movimento e não estático, como é pensado e defendido por muitos profissionais da Educação. Essa mentalidade não é aleatória, faz parte de uma política de docilização para uma dominação mais eficaz (FOUCAULT, 1975). A partir desta experiência, compreendi que se eu dançava para resistir às recusas das crianças em realizar as atividades escolares, passei a dançar para resistir às políticas e mentalidades mencionadas. A potencialização dos corpos na escola produz uma educação para autonomia prática e intelectual como um caminho sem volta.

As aulas dançantes ganharam uma proporção não esperada. Entendi, na época, que o que estava acontecendo em sala de aula não poderia ser encerrado naquele espaço. A comunidade escolar precisava conhecer o trabalho conjunto que estava sendo produzido. As músicas dançadas, cantadas e estudadas tornaram-se um Musical. Juntamos todas as músicas conhecidas por nós em um único arquivo e dançamos para toda a escola.

O processo de construção do Musical estendeu-se à pesquisa e produção de figurinos, localização no espaço cenográfico e pesquisa de gestos e movimentos da cantora. Para isso, vestimos fantasias carnavalescas, usadas por mim nos carnavais passados ${ }^{\mathrm{iii}}$, com adaptações à proposta do Musical. Assistimos alguns vídeos da cantora no YouTube e pesquisamos movimentos e gestuais, realizados por Carmem Miranda e pelos atores a sua volta. Foi um Revista Interinstitucional Artes de Educar. Rio de Janeiro, V. 7, N. 1 - pág. 549-555 janeiroabril de 2021: "Pedagogias Vitais: Corpo, Desejo e Educação" DOI: 10.12957/riae.2021.54889 


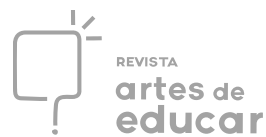

período de muito trabalho, amadurecimento e materialização da ideia. Finalmente, nos apresentamos à unidade escolar e, depois, com o incentivo da Coordenação Pedagógica, na ocasião, nos apresentamos na Mostra Regional e na Municipal da rede.

As atividades dançantes com as músicas da Carmem Miranda estenderam-se às músicas de Clara Nunes (1942-1983), seguindo a mesma sequência didática.

Ainda no mesmo ano, foi proposto, dentro da temática do PPP da unidade, agora nos anos 1950/1960/1970, um novo projeto. Desta vez, foram apresentadas às crianças músicas interpretadas por Clara Nunes. Além dos processos que o projeto Clara Nunes Show - uma coletânea de músicas, que foram dançadas pelas crianças - proporcionou, foi possível convidar os alunos à comparação entre as cantoras estudadas.

Uma das canções mais queridas e cantadas pela turma foi a Canto das três raças (1974), de Paulo César Pinheiro, interpretada por Clara Nunes. A partir desta música refletimos sobre as dores mencionadas pela letra da música. Desta forma, foi possível conduzir a discussão em torno das dores sofridas, ao ato de cantar como uma forma de resistir e reexistir em meio ao sofrimento.

As crianças demonstraram interesse também pelo ritmo da música, em especial pelo ritmo que os tambores davam à canção. Vários movimentos foram explorados por meio dos batuques ouvidos na música.

Outro aspecto a ser observado foi a proposta da personagem-artista apresentadas pelas cantoras. A análise das vestimentas das cantoras foi um dos destaques deste trabalho. Ambas tomaram a imagem das baianas dos anos 1920 para compor suas personagens artísticas (BRUGGER, 2008). A figura artística de Carmem Miranda criou uma fantasia carnavalesca de baiana, afastando-se bastante da baiana original, sobretudo das questões sociais e raciais que estão relacionadas à imagem da baiana da década de 1920. Carmem criou uma baiana glamourosa e cheia de ouro (BRUGGER, 2008). Muito diferente da baiana que vivia nos espaços públicos vendendo quitutes para garantir seu sustento diário. Por muito tempo, ainda hoje, a imagem mais carnavalesca e "brasileira" divulgada no exterior tem relação com o figurino criado pela referida cantora.

Clara Nunes, por outro lado, cria uma baiana bem próxima das mulheres negras que carregavam suas bandejas e frutas na cabeça para ganhar a vida. Clara Nunes foi uma grande pesquisadora sobre as tradições afro-brasileiras (BRUGGER, 2008). Suas músicas e vestimentas revelam um certo cuidado com a divulgação mais fiel do que é originário do povo afro-brasileiro. A baiana vestida por Clara não era idêntica à vestimenta usada pelas baianas originais, mas guarda uma semelhança com as roupas vestidas por elas. Além disso, suas Revista Interinstitucional Artes de Educar. Rio de Janeiro, V. 7, N. 1 - pág. 549-555 janeiroabril de 2021: "Pedagogias Vitais: Corpo, Desejo e Educação" DOI: 10.12957/riae.2021.54889 
músicas são um belo material de estudo e de sensibilização às questões delicadas (e perversas) da história do nosso país e da compreensão do "lugar" que a cultura e o povo negro ocuparam (e ocupam) no Brasil.

Há muitas questões (políticas, econômicas e raciais) envolvidas na análise do conteúdo das músicas e dos figurinos das cantoras. Provavelmente, as crianças da 1.203 (2017) não assimilaram todos os aspectos complexos do trabalho desenvolvido, porém as canções, as danças e os figurinos explorados foram uma espécie de semente lançada às questões de profunda importância para compreender debates que serão apresentados a este grupo em outro momento.

O processo de alfabetização das crianças da 1.203 foi entrelaçado por cantorias, danças e composição de figurinos. A análise dos textos (canções), exploração do significado de palavras, formação de frases que estavam em conformidade com o assunto discutido mobilizaram as crianças de uma maneira muito significativa, pois o processo de alfabetização não está vinculado apenas à leitura e à escrita de palavras, mas, sobretudo, compreender o mundo no qual estamos inseridos. Aprendemos, com Paulo Freire, que "a leitura de mundo antecede a leitura da palavra" (FREIRE, 1989, p. 09). A sensibilização que o dançar e as músicas trabalhadas proporcionaram foi fundamental para aprender a ensinar o que eles deviam e desejaram aprender: ler, escrever e contar. Desta vez, estudávamos enquanto dançávamos.

Tendo concluído o ciclo de produções em torno dos referidos projetos, foi observada uma mudança significativa no comportamento dos alunos. $\mathrm{O}$ trabalho realizado proporcionou amadurecimento emocional, intelectual e prático imensuráveis. A maneira como o coletivo se relacionava entre si e com os demais foi visivelmente alterado. Eles estavam mais autônomos, mais capazes e mais engajados com as propostas apresentadas para eles, assim como as realizadas por eles. Todos os aspectos positivos destacados reverberaram de maneira significativa na aquisição da leitura e da escrita. As crianças tornaram-se protagonistas do seu processo de aprendizagem.

Esta experiência me apresentou outra possibilidade de escola e outras formas de encaminhar as atividades escolares, que eu entendia como quadro, caderno, lápis e borracha. $\mathrm{Na}$ verdade, elas são consequência de um processo que acontece primeiro e permanentemente no corpo em movimento (MERLEAU-PONTY, 1999).

É preciso mover-se para aprender, seja criança ou adulto. O aprender está mais relacionado com o movimento, do que com o estático que nós, escola, promovemos. A valorização e a inclusão do corpo no contexto escolar têm se revelado a mim como um campo Revista Interinstitucional Artes de Educar. Rio de Janeiro, V. 7, N. 1 - pág. 549-555 janeiroabril de 2021: "Pedagogias Vitais: Corpo, Desejo e Educação" DOI: 10.12957/riae.2021.54889 


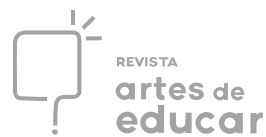

de potência de engajamento, ensinagem, aprendizagem, produção criativa e, principalmente, como um caminho possível de aquisição de autonomia diante da vida. Além disso, a valorização e a inclusão do corpo nos processos de ensino-aprendizagens corroboram para um tipo de relação e/ou vínculos que são únicos para que o trabalho pedagógico se efetive, sobretudo no processo de Alfabetização.

A professora Patrícia Corsino (2013), nos ensina que a "alfabetização não tem receita, mas tem princípios"; um deles é o movimento. Para o coletivo em questão, a Dança foi o movimento que deu certo. Entretanto, é preciso dizer que existem outros. Outros moveres que devem ser explorados, investigados, observados. Como o grupo atendido por você se move? Como você entende e percebe esse movimento? Há incômodo ou encantamento? Como ele interfere nos fazeres em sala de aula? Essas são perguntas que precisamos realizar a nós mesmos antes de aprisionar os corpos nas carteiras.

Enxergar as potencialidades existentes no corpo em movimento é fundamental para uma educação que pense na construção de seres humanos melhores e dispostos a relações mais saudáveis.

\section{REFERENCIAS}

. Ministério da Educação. LDB - Lei no 9394/96, de 20 de dezembro de 1996. Estabelece as diretrizes e bases da Educação Nacional. Brasília: MEC, 1996.

. Base Nacional Comum Curricular (BNCC). Educação Infantil. Brasília, MEC/CONSED/UNDIME, 2017. Disponível em: < 568 http://basenacionalcomum.mec.gov.br/images/BNCC_publicacao.pdf>. Acesso em: 24 fev. 2019.

. Resolução CNE/CEB 5/2009. Institui as Diretrizes Curriculares Nacionais para a Educação Infantil a serem observadas na organização de propostas pedagógicas na Educação Infantil. Diário Oficial da União, Brasília, 18 de dezembro de 2009, Seção 1, p. 18.

BRÜGGER, S. M. J. "O povo é tudo": uma análise da carreira e da obra da cantora Clara Nunesa. Revista ArtCultura. Uberlândia, v. 10, n. 17, p. 191-204, jul.-dez. 2008

CORSINO, P. Alfabetização não tem receita, mas tem princípios. Disponível em: <https://pt.slideshare.net/terccre/alfabetizao-no-tem-receita-mas-tem-princpios-patrciacorsino $>$. Acesso 03 mar. de 2019.

FOUCAULT, M. (Trad. de Raquel Ramalhete). Vigiar e punir: nascimento da prisão. Petrópolis, Vozes, 1987.

FREIRE, Paulo. A Importância do ato de Ler. São Paulo: Cortez/Autores Associados, 1989. Revista Interinstitucional Artes de Educar. Rio de Janeiro, V. 7, N. 1 - pág. 549-555 janeiroabril de 2021: "Pedagogias Vitais: Corpo, Desejo e Educação" DOI: 10.12957/riae.2021.54889 
MERLEAU-PONTY, Maurice (Trad. Carlos Alberto Ribeiro de Moura). Fenomenologia da percepção.- 2- ed. - São Paulo : Editora Martins Fontes, 1999.

\footnotetext{
${ }^{\text {i }}$ Professora do Ensino Fundamental I (SME/RJ). Graduada em Pedagogia (UFF). Graduanda em Filosofia (UERJ). UERJ. Rio de Janeiro / Brasil. ORCID: https://orcid.org/0000-0003-1207-2733.

ii Fiz parte de um grupo tradicional de Frevo na cidade do Rio de Janeiro ao longo da minha adolescência. O nome do grupo é "Frevo Prato Misterioso".

iii Fiz parte de um grupo tradicional de Frevo do município do Rio de Janeiro e guardei todas as fantasias que ganhei ao longo da minha trajetória. Foram essas fantasiais que utilizamos para produzir as mirandetes.
} 